\title{
Dilatation and Diverticulum
}

National Cancer Institute

\section{Source}

National Cancer Institute. Dilatation and Diverticulum. NCI Thesaurus. Code C161548.

A finding indicating the presence of dilatation and diverticulum in a tubular anatomic structure. 